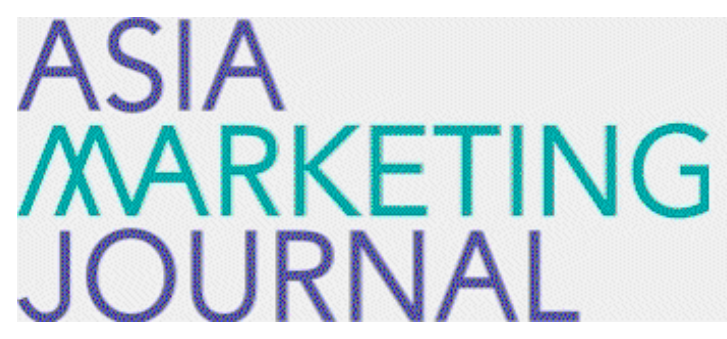

ASIA MARKETING JOURNAL

Volume 22 | Issue 4

Article 9

$1-31-2021$

\title{
Connect, BTS: An Example of Innovative Transmedia Branding To Rethink Spatiality and Meaning-making
}

Stefania Piccialli

Follow this and additional works at: https://amj.kma.re.kr/journal

Part of the Marketing Commons

\section{Recommended Citation}

Piccialli, Stefania (2021) "Connect, BTS: An Example of Innovative Transmedia Branding To Rethink Spatiality and Meaning-making," Asia Marketing Journal: Vol. 22 : Iss. 4 , Article 9.

Available at: https://doi.org/10.15830/amj.2020.22.4.151

This Article is brought to you for free and open access by Asia Marketing Journal. It has been accepted for inclusion in Asia Marketing Journal by an authorized editor of Asia Marketing Journal. 


\title{
Connect, BTS: An Example of Innovative Transmedia Branding To Rethink Spatiality and Meaning-making
}

\author{
Stefania Piccialli*
}

This case study research analyzes the cross-artistic project Connect, BTS and its relationship to transmedia branding, meaning-making and spatiality. After an overview of the argument and a section on methodology, the reader will find the analysis of the case study. Thanks to the use of a qualitative approach, this examination of Connect, BTS unveils the ways in which this initiative becomes a location that allows a reconceptualization of space that fosters plurality, exchange, and subjectivity. Connect, BTS unites seemingly incompatible fields under one project, favoring the co-creation of meanings among different artists, BTS, ARMY (the group's fans), business partners and viewers. This process has been investigated through content analysis, exploring Connect, BTS's transmedia strategies from branding to storytelling, to evaluate their efficacy in regard to brand identity, brand experience, and brand trust. The paper will also explore the variety of layers and spatial dimensions contained in Connect, BTS, which flow from art to the music industry, material and digital space, various market sectors and media. In light of this, Connect, BTS embraces a galaxy of separate semantic units into an extended liminal continuum that does not discount difference.

Keywords: Connect, BTS - BTS - Transmedia Branding - Transmedia Storytelling - Spatiality

\section{Introduction}

When thinking of BTS, their artistry and brand, one of the main distinctive characteristics that come to mind is transmedia praxis. The presence of the group on multiple platforms and media extends to a variety of different areas: music and MVs, video games, social media, radio, websites, books, and digital and traditional art. This cross-spatial exposure allows for diverse audiences to discover and interact with the group's content, making transmedia strategies an effective technique to engage numerous target markets and to expand the pool of potential buyers interested in the BTS

\footnotetext{
* MA Via Marchese di Montrone (stefania.piccialli@gmail.com)
} 
brand. The extent to which BTS's narrative and artistic universe branches out in different milieux not only does it bridge cultural differences but also spatial borders, overcoming the perceived divide between the physical and the digital spheres. In this sense, the tendency of transcending space and boundaries is reflected in the marketing practices of the group, especially within transmedia branding. It allows BTS to reach various media and to make use of different storytelling methods to attract an increasingly diversified audience. By mainly employing Jenkins's framework on transmedia (2006) and Yin's (2014) case study methodology, this piece of research will explore the cross-artistic project Connect, BTS. Launched in January 2020, this initiative has been defined as a "global project to connect five cities and twenty-two artists, each of whom contributes their unique philosophy and imagination to it. This project aims to redefine the relationships between art and music, the material and immaterial, artists and audiences, artists and artists, theory and practice" (Big Hit Entertainment 2020). From this official presentation, Connect, BTS locates itself as a cross-artistic initiative that favors the encounter between diverse forms of art and spatial dimensions (e.g. digital and virtual spaces, augmented reality, different cities and exhibition sites, artistic fields, and market sectors). This case study provides a notable and timely example of the ways in which spatiality can be reconceptualized in favor of a transmedia galaxy, different from rigid sectorial thinking and shapeless flows of information. Each semantic sphere, form of art or brand maintains its unique characteristics but also allows media and meanings to flow from one to the other through practices of transmedia storytelling and branding. This synergic engagement fosters the union of seemingly different milieux under one project, and makes Connect, BTS a project worth researching for its marketing, semantic and spatial implications. Moreover, it represents a valuable object of study on BTS's brand and role in the contemporary artistic and marketing global stage, as one of the leading popular culture players in this landscape. This paper will investigate Connect, BTS on three levels. Firstly, it will determine the role that transmedia storytelling plays within Connect, BTS and it will delineate the process of co-creation of meanings shared among BTS, ARMY (their fans), business partners and artists. Secondly, it will explore the elements that position the case study as a location to reconceptualize space in regard to meaningmaking and as an attempt to overcome gaps and boundaries between different sectors. Lastly, it will examine the relationship between transmedia branding strategies and BTS's brand identity to better understand the relationship between these marketing techniques and meanings associated with the band. After the discussion of the research questions and methodology in the first section, the second part of this paper will dive into the analysis of the chosen case 
study, culminating in the conclusions, which will wrap up this inquiry by summarizing the overall argument and advancing suggestions for future research.

\section{Research Aims and Questions}

To a) delineate the relationship between Connect, BTS and transmedia storytelling and branding and $\mathrm{b}$ ) to unveil its connection to spatiality and meaning-making, this paper will explore the following research questions:

1. How is space reconceptualized in Connect, BTS? How do spatiality and transmedia practices inform each other in Connect, BTS?

2. How do the transmedia branding and storytelling techniques employed for Connect, BTS influence the process of $\mathrm{co}^{-}$creation of meanings among BTS, their audience, their business partners and other artists?

3. How do BTS innovate the ways in which space is thought of in relationship to art, brand identity and meaning-making?

These research questions are going to be developed in accordance with the following literature and methodology.

\section{Literature Review}

\subsection{BTS(방탄소년단-Bangtan Sonyeondan)}

The existing literature on BTS is newlyemerging and rich. It addresses a variety of different themes such as artistry and musical narrative (Doré and Pugsley 2019; Wong 2020; Balmain 2018), transnational fandom and participatory culture (Eaglehawk 2020; McLaren and Jin 2020; Irwansyah and Lestari 2020; Lee and Nguyen 2020; Koh and Baek 2020), translation and translinguality within ARMY (Lee 2018; Aisyah 2017; Baker 2019), marketing and brand loyalty (Jääskeläinen 2019; Lee and Kim 2020), product consumption (Kwak et al. 2019), text mining and digital content business (Choi, Park and Kim 2019) and fashion theory (Kim 2019) among others. In these works, spatiality in relationship to BTS is primarily investigated in its tie to social media and transcultural fandom dynamics, highlighting the spatial quality of the relationship between BTS and ARMY. The latter pushes for the creation of meanings, which are shared, elaborated, developed and discussed in a shared space between the group and its fandom or among members of the ARMY themselves. By affirming that transcultural fandoms foster the "interrogation of contexts and identities beyond categories of the nation" (2020), McLaren and Jin offer a valuable suggestion 
concerning the ways in which BTS encourage a reconceptualisation of space. Within a crosscultural community like ARMY, boundaries between nations blur in favor of a shared interest, and subjective difference is cherished more than relegated to the realm of seemingly unbridgeable national, linguistic and cultural gaps.

\subsection{Space And Spatiality}

Although this paper will not attempt to delineate an analysis of the complexities of space and spatiality as it would derail the discussion at hand and go way beyond its scope, it is important to pinpoint the academic landscape within which this paper can be located. Space and spatiality are inextricably tied albeit not superimposable a nd interchangeable. Space has been investigated both as the material conditions of being an environment and as a social product of human and/or non-human interactions (Lefebvre 1991; Malpas 2012; Reichenbach 1958; Soja 2010). In this sense, the implications of the concept of space branch into various disciplines and form an everevolving discourse upon which the concept of spatiality is built. Defined by Wei (2015) as "any property relating to or occupying space such as dimensionality, directionality and spatial configuration", spatiality acquires not only physical but also relational qualities. Whether it signals the relationships among spatial properties, the inhabitants of a certain site, of different mediums working within or around a space or between the human and the spatial, "spatiality actively integrates human and space" (Zimmerman and Saura 2016). It is humans who conceptualize space and assign meanings to the relationships that take place between their inhabitants (people or non-human) and the environments they occupy. In this sense, Shoorcheh's theorization of space (2019) offers a valuable perspective on the positioning of space and spatiality, as he identifies space as a pre-existing context within which spatialities are made possible or impossible, making the latter "the spatial dimension of human agency. Spaces and spatialities are inseparably involved in a multiple-feedback system. Spatialities produce spaces, while spaces condition spatialities" (Shoorcheh 2019). The mutual exchange that occurs between the two is made possible by human and non-human inhabitants, which negotiate how they occupy and are linked to the spatial dimension of their worlds. Lévy (2014) encoded this principle by distinguishing between the environmental (space) and the action (spatiality), to underline that space constitutes the canvas upon which occupants enact spatialities by living in a certain environment and elaborating its meanings. To understand the concept of spatiality in relation to BTS, a notable contribution to take into consideration is Jiyoung Lee's “BTS, Art Revolution” (2019). In the book, she introduces two concepts tied 
to spatiality and BTS: horizontality and the rhizome. Drawing from Deleuze's philosophy, Lee (2020) defines the concept of the rhizome as a "horizontal connection without a singular center $[. .$.$] in opposition to the hierarchical and$ centered structure of trees". She also speaks of BTS as a group that fosters "horizontality", a phenomenon that extends "across borders and flows across the entire world" (Lee 2019). The stress on multiplicity and on the elimination of a presumed hierarchy of spaces in BTS's work is going to be the center of this piece of analysis, building on Lee's rhizomatic horizontality to extend the concept outside of the realm of social change. It will draw from Foucault's (1984) relational qualities of space, and extend the relationships among sites that he viewed as "irreducible to one another and absolutely not superimposable on one another" (Foucault 1984) to a horizontal and rhizomatic perspective. In this regard, Connect, BTS operates to favor the encounter between diverse forms of art and spatial dimensions (e.g. digital and virtual spaces, augmented reality, different cities and exhibition sites, artistic fields, and market sectors), to encode cross-artistic and transmedia praxis in a spatial paradigm. Within this framework, the ways in which BTS's artistry and brand identity operate can be located in the realm of transmedia praxis. It branches out to a variety of platforms, media and artistic outlets, engendering a creative and narrative universe.

\subsection{Transmedia Storytelling and Transmedia Branding}

Another core construct that will be employed in this research to investigate Connect, BTS is transmedia praxis, more specifically, transmedia storytelling. According to Jenkins (2007), "transmedia storytelling represents a process where integral elements of a fiction get dispersed systematically across multiple delivery channels for the purpose of creating a unified and coordinated entertainment experience”. To better accommodate the definition of transmedia storytelling to contemporary utterances, Jenkins revised and enriched his original vision, linking it to Marsha Kinder's "transmedia intertextuality" (1991). In her work, Kinder viewed transmedia intertextuality as a "supersystem", a functional space that is interlinked and pluralistic, manifold and flexible (2016). Jenkins acknowledged the ever-changing nature of the theorization of transmedia, which he stated should be investigated in depth in terms of the relation between media, rather than counting the number of concerned platforms. In this way, it is possible to "imagine a continuum of possibilities" (Jenkins 2011). Jenkins and Kinder's theoretical framework constitutes the space where Connect, BTS positions itself as an example of transmedia praxis. The project contributes to the universe of BTS's content and expands it, transforming that intertextual supersystem into a transmedia galaxy that encompasses the realms of art, 
entertainment and marketing.

Despite its fairly recent development, literature on transmedia branding investigates the impact of intertextual cross-media strategies in a variety of contexts such as prosumer engagement (du Plessis 2019; Sokolova 2012), journalistic news brands (Costa-Sánchez, Rodríguez-Vázquez and López-García 2017), BAMMs (Black American Media Moguls) (Everett 2014), embodied branded experiences such as conventions and fan celebrations (Hills 2018), native advertising (Matteo and Dal Zotto, 2015), HBO and the American televisual marketplace (Bourdaa 2014), event, tourism and online marketing (Campillo-Alhama and MartínezSala, 2019), and gamification and brand image (Feng 2014). These studies highlight the need in both academic and marketing settings to overcome a strictly narratological take on transmedia strategies, examining the irrelevance“ from a multidisciplinary perspective encompassing the marketing aspect" (Derhy Kurtz 2014). This paper and many of the aforementioned studies rely on Tenderich's (2013) definition of transmedia branding, which is illustrated as follows: "Building on Jenkins' definition, transmedia branding is defined as a communication process in which information about a brand is packaged into an integrated narrative, which is dispersed in unique contributions across multiple media channels for the purpose of creating an interactive and engaging brand experience" (Tenderich 2013). Tenderich's polisemantic take contributes to Scolari's (2009) perspective that delineates the importance of semiotic exchanges that "stimulate the financial markets" (Scolari 2009). From his standpoint, persuasive advertising has been overcome in favor of the more timely and ambitious goal of creating brands as symbolic universes that "can produce a discourse, give it meaning, and communicate this to audiences" (Scolari 2009). Both Tenderich (2013; 2014) and Scolari's (2009) work stresses the importance of plurality to build and foster a solid brand identity, which in turn creates semantic richness and a wider brand awareness. Connect, BTS ought to be regarded as a perfect example of the application of this framework on transmedia branding, as its nature as a collective curatorial experience targets various audiences. The exhibition's focus on interactivity and participation incites consumer engagement, allowing for brand awareness and brand loyalty to deepen. Consequently, the employment of collective intelligence in transmedia praxis allows the brand adapt to an ever-changing media and market landscape (Feng 2014).

\section{Methodology}

\subsection{Case Study Method}

The research questions will be explored 
through the employment of a qualitative approach and by following the case study method developed by Robert K. Yin (2014). The latter defined the case study method as "an empirical inquiry that investigates a contemporary phenomenon within its real-life context, especially when the boundaries between phenomenon and context are not clearly evident" (Yin 2009). Within this framework, information is inferred from the observation of a phenomenon immersed in a non-controlled environment where the researcher cannot intervene in the present events. Yin underlines the importance of containing the analysis of the selected case or cases within a series of "why" and "how" questions and more specific propositions that determine the validity and scope of the study (Yin 2009). Following this method, the research questions have been designed to investigate a single case study, Connect, BTS. This cross-artistic project developed by Big Hit Entertainment and BTS alongside with twenty-two creatives serves as a timely example to illustrate a contemporary phenomenon within its real-life context, creating a correspondence with the "descriptive type" of case study method (Yin 2009). The selection of one case as opposed to multiple cases led to the choice of proceeding with a "holistic" design (Yin 2009), as Connect, BTS will be examined as a single research unit. This paper analyzes the implications of this artistic project not as separate subunits but in relationship to the whole case, underlining its importance in regard to transmedia praxis and spatiality. Lastly, the case study approach is particularly valuable in light of this research, as following Yin's definition, this method does not deliberately "divorce a phenomenon from its context" (Yin 2009). The blurring of boundaries between phenomenon and environment mirrors the overall theme of this analysis: revealing the potentially beneficial qualities of viewing distinct spaces and fields as an overlapping galaxy of locations as opposed to a disjointed whole, fragmented in presumably separated sectors.

\subsection{Qualitative Approach and Content Analysis}

The space dedicated to the case study research will be contained within the framework of a qualitative approach. The analysis of Connect, BTS will be carried out in an interpretative fashion by inferring meanings from the case. In particular, content analysis will be the primary lens to attempt to answer the proposed research questions. Krippendorff defined content analysis or CA as "a research technique for making replicable and valid inferences from texts (or other meaningful matter) to the contexts of their use" (2004). The deductive features of this technique align themselves with the purpose of this paper, which will employ the case study as the selected example from which information is drawn and elaborated. Given that textual 
information will be the center of the analysis, there is a clarification to be made regarding the chosen methodology. The discussion of Connect, BTS will take into consideration a variety of utterances, creating contact points between CA and discourse analysis (DA). Gheyle and Jacobs (2017) point out the interrelation between the two approaches, deeming content analysis "a distinct methodology from "discourse analysis' (or other types of textual analysis, such as rhetorical or conversational analysis), while maintaining that within the containerterm of content analysis, there is a continuum of quantitative and qualitative approaches to using it". Within this methodological liminality, the exploration of the case study will include the deconstructive qualities of DA as a supplement to the knowledge gained through CA, which is focused on the "prevalence of ideas in texts" (Gheyle and Jacobs 2017) instead. Before diving into the investigation of Connect, BTS, it is important to deliver one last point concerning methodology. In his work, Yin has problematised case study research as a traditionally "soft form of research" (2009) which may contain hard or "scientific" strategies (e.g. triangulation). The use of the aforementioned methods and approaches in this paper integrates the structure of methodological rigor with interpretative and inferential analysis. It does not aim at offering quantifiable data, but rather, deductive theorization.

\section{Discussion}

\subsection{Connect, BTS, Spatiality and Meaning-Making in the Transmedia Galaxy}

The ways in which BTS's artistry and brand identity operate can be located in the realm of transmedia praxis. It branches out to a variety of platforms, media and artistic outlets, engendering a creative and narrative universe. The galaxy of products and content that BTS share is not only made to be bought and consumed, but also elaborated and reinvented, acquiring new meanings. This process of communal meaning-making finds fertile ground in transmedia practices, above all, storytelling. Although not all of BTS's transmedia content falls into the category of fictional storytelling as described in Jenkins's work (2007), the majority of the transmedia presence that BTS offers their audience builds a narrative, whether it be fictional or otherwise that exposes parts of their life, artistry, and business ventures. The work and media presence of the group integrates multiple transmedia elements, from the narrative universes expanded and hidden within albums and promotional content (e.g. The BTS Universe stemming from the record The Most Beautiful Moment in Life) to intertextuality, in which meanings can be traced back from ARMY's social media to 
BTS’s MVs, or "multimodality" (Jenkins 2011), through which BTS show different sides of their lives on and off stage thanks to different modes of representation such as social media, reality TV or film. This plurality in spaces, relationships and representations makes BTS the holders of a transmedia supersystem. However, considering the variety of utterances that work together to build, share and develop BTS's messages, Kinder's concept can be pushed even further to speak of a transmedia ecosystem, in which the interrelation between media becomes a synergic effort to exchange information and produce new material.

Connect, BTS positions itself in this transmedia ecosystem as the widest BTS project to encompass diverse media and, more broadly, different spaces. In this respect, the title of the event "Connect, BTS" already makes it evident that the initiative aims at uniting different spheres, bridging gaps and conciliating supposedly opposite realms. At the same time, the convergence of multiple spaces seems not to discount difference, as the uniqueness of each artist and medium is preserved and cherished. The continuation of the official statement continues as follows: "Connect, BTS may be described in terms of a collective curatorial practice by curators around the world who resonated with BTS' philosophy" (Big Hit Entertainment 2020). The redefinition of relationships between different spaces thus merges with a communal experience of creation of meanings that occurs through a collective curatorial experience. As the collaboration between curators occurs, new meanings can arise thanks to the multiplicity of viewpoints and cultural perspectives of the involved professionals. At the same time, the artists' visions come into play, as well as BTS's philosophy, mixing different fields of artistic expertise aligned with the group's established core values.

Messages of self-love, high quality art, identity negotiation, mutual care and speaking one's truth correspond to the characteristics that define not only BTS's philosophy, but also their brand. An effective synthesis of the group's marketing strategies up until 2019 can be found in Petra Jääskeläinen comparative work (2019), where she underlines the efficacy of crossplatform use and of mixed localized and glocalized approaches. A versatile employment of multiple media, mainly SNS, offers the opportunity to fans and viewers of engaging with BTS's free content (Jääskeläinen 2019), building familiarity with the brand. Moreover, Big Hit Entertainment's focus on innovating customer experience and expanding the value chain aims at extending the BTS brand experience with a variety of approaches to secure the impact and influence of these stars within the national and international markets (Jääskeläinen 2019). Connect, BTS can be considered an example and a development of such strategies. The glocalized curation of this project that took place in Seoul and in other four international cities caters to both 
global and local consumers, overcoming what Featherstone, Lash, and Robertson (1995) defined the presupposed "polarity between local assertions and globalizing trends". In this sense, Connect, BTS positions itself yet again as a site for the reconceptualization of space. Within the scope of the project, the global and the local do not override each other, but rather they work synergically to reassert the core values of the BTS brand. In this sense, transmedia branding serves as a tool for convergence to expand the brand experience in Connect, BTS. Tenderich (2014; 2013) regards the relationships between transmedia practices and brand identity as a connection that presents an interdependence between marketers and consumers. Therefore, interactivity becomes a key factor between ARMY and BTS - fandom and artist - as potential buyers, producers, and marketers all maintain an ecosystem of meaning-making that corroborates the brand. The audience's agency in this process allows it to become an extended member of an organization's branding team (Tenderich 2014), and this is made possible also thanks to transmedia praxis. BTS are not new to cross-media projects, however in Connect, BTS they manage to expand the opportunities to co-create meanings (Coombs \& Holladay 2018) by multiplying the spaces in which it is possible to elaborate, rework and produce meanings.

\subsection{Connect, BTSS Transmedia Branding: Promotional Strategies and Collaborations}

For this project, the transmedia branding strategies of the group have embraced promotion, the launch of a new partnership, and have championed brand awareness. To offer ARMYs and viewers multiple opportunities to engage with the many different products of the group (Stork 2014) and with the members themselves, both the exhibitions and the promotion for Connect, BTS occurred within the interconnected transmedia space. The launch of the project had been publicized on Twitter, featuring BTS members and hints to the upcoming initiative from two of their official profiles (bts.bighitofficial and bts_twt), supporting the initiative even after its inauguration on the same platforms and on Big Hit Entertainment's account (BigHitEnt). Hyperlinks connecting the tweets to other media such as Naver articles (Big Hit Entertainment 2020), the official website for the project (BTS 2020a) and YouTube (BTS 2020b), allowed the audience to familiarize themselves with the forthcoming events, getting to know the works of art and their creators in a networked fragmentation of information. Through these transmedia promotional strategies, BTS managed to reiterate their brand identity while also expanding their reach to another artistic industry, therefore reinventing and enriching their image to attract an even wider audience. 
Transmedia storytelling developed through Twitter, the official Connect, BTS website and YouTube allowed BTS to co-create meanings not only with the selected artists and curators, but also with ARMY and the audience invited to participate in the discovery of the project. The rich transmedia participation of BTS members during the promotion of Connect, BTS cultivates brand trust, as consumers knew, when exposed to the new project, that they could depend on the brand's abilities to vouch for product function (Lee and Kim 2020; Erdem and Swait 2004). In other words, BTS's attitudes and communication heightened their reliability, minimizing the audience's perceived risk in investing in a new product and encouraging product consumption (Kwak et al. 2019). In this sense, BTS brand trust exerted a positive effect on BTS brand loyalty, as ARMY prefer a specific brand (BTS) when purchasing a product, and repeatedly buy from that brand (Lee and Kim 2020). However, the case of Connect, BTS further complicates this dynamic. The five art shows presented within the scope of the project were all completely free of charge (Dex 2020), offering accessible spaces to all kinds of audiences to interact and engage with the artworks.

This product's availability and democratization exposes the project and, consequently, the BTS brand to ever-growing and increasingly diversified target markets - from varied age groups to geographically different customers, or clusters of buyers with differing behavioristic features and interests such as music fans, ARMY, members and public of the art industry, niche audiences, and buyers interested in technology. The last target market has been included in light of Connect, BTS, as the latter represented the starting point of the partnership between Samsung and BTS (Yonhap 2020).

This collaboration proved itself to be significant not only for marketing purposes, but also in terms of spatiality and meaning-making. The exhibitions in all five cities feature an AR service provided by Samsung "that Galaxy phone users can download to access a virtual reality experience of Connect, BTS. [‥] A member of BTS (RM, Jin or Jungkook) will appear virtually on screen to talk about specific artwork from the series" (Kim 2020). The augmented reality experience grants advantages to both brands, as the mutual access to customer pools widens the array of potential buyers as well as building longevity in brand trust and loyalty (Chaudhuri and Holbrook 2002). The presence of BTS members in yet another medium allows the audience to recognise both the musicians and the tech brand, enriching not only the meanings that can be absorbed on the works of art but also on the merging of different industries in one liminal space between physical and virtual reality. In this transmedia context, BTS's brand identity remains intact, as its core values do not change in light of the Samsung partnership. If anything, they are 
solidified within Connect, BTS, reiterating the project's overarching theme of re-defining relationships between individuals, companies, and modes of expression. In this sense, Connect, BTS blurs the apparently sharp and fixed boundaries between the different spaces of market sectors, fields and dimensions, combining physical and virtual realities to create a favourable marketing ecosystem that BTS created for their own brand. Ultimately, the trans-spacial and transmedia expansion of BTS's brand identity through Connect, BTS includes the music, art, and tech industries and represents a possibility to foster audience engagement with the brand and products. As Yang \& Zisiadis (2014) affirm, "creating audience participation through transmedia storytelling in marketing campaigns for movies, products and services can be beneficial". More research should be carried out to estimate the extent to which Connect, BTS has been profitable for BTS and Big Hit Entertainment both in South Korea and globally, however, this project ought to be considered without doubts a site for meaningful marketing exploration. In terms of brand identity, transmedia branding and meaning-making, thanks to the multimodality attained by being represented in various media such as visual art, the internet and social network services, Connect, BTS well-exemplifies liminality of space in meaning-making and transmedia praxis. This project therefore constitutes a large-scale and conscious effort in uniting different artistic fields, brands and even countries under one enormous initiative that positions BTS as innovators in the music and art industries.

\subsection{The Semantic Qualities of the Transmedia Galaxy}

The interactive qualities that stem from the transmediality of Connect, BTS provide fertile ground where audiences, artists, producers and curators can participate in the process of $\mathrm{co}^{-}$ creation of meanings. Starting with the selection of the artists, each of them has taken part in the transmedia campaign of the project, disclosing their views not only in their works of art, but also in interviews with BTS themselves and through the descriptions offered on Connect, BTS's website (Big Hit Entertainment 2020). Almost all of the exhibitions have been presented through an invitation letter uploaded to the website and crafted by BTS to reveal part of the curatorial process through transmedia storytelling. The interviews and letters correspond to visible interactions between artists of different expertise and fields uniting for the sake of the project with their unique vision. Moreover, spatiality is further layered as each exhibition was developed both in physical spaces and in video galleries that represent part of the creations with artists' commentaries. In this respect, "the spaces represented in artistic texts are not exhausted in a mimetic relationship with the space of the extratextual world, but 
bear a semiotic, meaning-generating function" (Saldre and Torop 2012). In Connect, BTS the fragmentation of messages does not dilute the values of the project nor of the BTS brand, adding new semantic spheres that can be occupied, transformed and created between creators and audience. This process is also visible in the artistic exploration of the selected works, installations and performances. In Stephanie Rosenthal's Rituals of Care, the diverse languages of corporeal responses and performance art meet the spaces of the Gropius Bau, a "wounded" building which was bombed during the Second World War and whose "scars" were deliberately left visible as a way to preserve its historicity. In Catharsis, Jakob Kudsk Steensen reimagines the landscape of a grown forest through 3D technology to underline the link between media and ecology, creating a visual naturalistic portal to spark reflection on present and past environments. In Aerocene Pacha, Tomás Saraceno explores aerial space by offering an experience in a flying museum, in which the vision of a world and of ecosystems free from the threat of fossil fuels is tangible, uniting space and time. In New York Clearing, Antony Gormley invites viewers to immerse themselves in an open space, in which they become active agents in the completion of the work, reaffirming the power of lived experience. In Grey, Pink and Yellow, Ann Veronica Janssens tests the limits of perception, sharing an installation that provokes different reactions as the space within which it is encased changes, and within which visitors can explore their own materiality. Lastly, in Beyond the Scene, Yiyun Kang reimagines BTS's choreographies through mapping and large-scale projections to display the ways in which the group and ARMY grow and populate space together (Big Hit Entertainment 2020). In this brief summary of the artworks that comprise Connect, BTS, space is interpreted, multiplied, reimagined, offered to the viewers and shaped alongside them. Meanings are therefore co-created, extracted from the transmedia universe of the project to circulate within its manifold and co-existing spaces. As the Art Director of the project Daehyung Lee argued when speaking about the typeface created for the initiative, "the CONNECT typeface creates connections through its bitmap-based sculptural characteristics that defy artificial curves in a gesture of solidarity for the non-conforming oddities that connect and enrich us through diversity across the world as they reevaluate their present circumstances, attitudes, and potentialities" (Lee 2020). Connect, BTS becomes a galaxy of semantic possibilities, as diverse storytelling methods and media representations converge in one ecosystem. In this sense, Connect, BTS participates in the shift from a "space of places" towards what Castells (1999) calls the "space of flows", in which "the material arrangements allow for simultaneity of social practices without territorial contiguity”. The synchronous presence 
of multiple digital and physical spaces allows individuals to form relationships and to value differences, eliminating gaps and divides between areas of interest, fields, utterances and, ultimately, experiences.

\section{Conclusion and Implications}

This case study research on Connect, BTS aims at providing answers to the three initial research questions:

1. How is space reconceptualized in Connect, BTS? How do spatiality and transmedia practices inform each other in Connect, BTS?

2. How do the transmedia branding and storytelling techniques employed for Connect, BTS influence the process of co-creation of meanings among BTS, their audience, their business partners and other artists?

3. How do BTS innovate the ways in which space is thought of in relationship to art, brand identity and meaning-making?

Through this project, the BTS brand has managed to offer an alternative to the fixed boundaries of sectorial thinking in favor of a spatial continuum, an extended liminal space where meanings can be created, negotiated and shared. Expanding the notion of rhizomatic acentrality (Lee 2020), Connect, BTS offers in its promotional material and exhibitions multiple different and non-hierarchical spaces. These promote social change andexpand communication, human expression, and a vision of transmedia branding towards spatial multiplicity. Transmedia practices favor the creation of this kind of innovative spatiality thanks to their fragmented narrative qualities, and in turn influence this cross-media galaxy by shaping it through its intrinsic participatory and collective properties.

This same plurality and active meaningmaking processes allow sufficient openness to grant a space to co-create meanings among BTS, their audience, their business partners and other artists. In regards to this, Ibrus and Ojamaa (2014) assert that "nurturing intersemiotic translations could mean the introduction of not only a new mainstream mechanism for generating new meanings, but also, due to the participatory traits of transmediation, a mechanism for filtering out the most accepted and consensual ones. In this way, transmedia has the potential for facilitating societal dialogues that both condition change as well as eventually bring about new stabilities". Transmedia practices then become a tool to broaden and diversify the number of media and the modes of storytelling, so that multiple perspectives can co-exist and foster the creation of semantic spheres. Transmediality in branding and storytelling influences the amount of interactivity within Connect, BTS. Therefore, the exchanges created 
in this context allow for meanings to be reinvented and shared in a process of mutual communication and collective intelligence.

Connect, BTS represents an example of innovative spatial thinking as BTS and the artists involved in the project invite viewers to overcome dichotomies among different spatial spheres. They push for a liminality that encourages open-mindedness and embraces diverse subjectivity, plurality and flexibility at the same time. As space is reconceptualized in a flow of multiple dimensions, fields, artistic forms, industries and media into one, branding techniques branch out towards multiple media (video, SNS, Youtube, live exhibitions) and attract different potential consumers (ARMY, members and public of the art industry, niche audiences, and buyers interested in technology). The BTS brand thus unites many people from different walks of life by both expanding its reach and media expressions, but also by creating with Samsung a more enticing brand experience that may help buyers solidify brand trust and brand loyalty.

This analysis of Connect, BTS does not constitute a complete delineation of successful transmedia storytelling and branding techniques, nor does it attempt at offering practical implications to marketers. Rather, with the example of the case study it aims at providing a theoretical lens through which transmedia spaces can be conceptualized to foster a more beneficial context for strengthening brand identity and brand exposure (Yang \& Zisiadis 2014). The creation of cross-media promotional campaigns and events that dare to unite different milieux and brands results in fertile opportunities for marketers to build and solidify brand identity. Moreover, the shift in perspective from rigid boundaries or shapeless openness towards a liminal galaxy where difference is valued as much as flexibility can also represent a useful spatial lens in both academic and non-academic marketing settings.

In this sense, this study proposes an up-todate contribution to the discussion on the impact of the notions of spatiality in pop culture, transmedia branding and marketing. The exploration of Connect, BTS and its semantic and spatial implications concerning transmedia branding and storytelling provides a qualitative interpretation on such topics, which have never been explored combined. The media and marketing scholarship on BTS is only recently starting to flourish in the contemporary debate. Therefore, more research is encouraged to be undertaken regarding the efficacy of marketing techniques and of transmedia branding strategies in Connect, BTS and other 2020 initiatives that BTS have pursued before, during, and after the COVID-19 pandemic to. In this way, scholars and marketers alike will better understand the implications of longevity and successfulness of the group's transmedia marketing practices and spatial framework. 
〈Received December 15. 2020〉

〈Accepted February 5. 2021〉

\section{References}

Aisyah, Aznur (2017), "Korean-English Language Translational Action of K-Pop Social Media Content: A Case Study on Bangtan Sonyeondan's (BTS) Official Twitter," 3L: The Southeast Asian Journal of English Language Studies, 23(3), 67-80.

Baker, Judy-Gail (2019), “BTS’ A.R.M.Y. Web 2.0 Composing: Fangirl Translinguality As Parasocial, Motile Literacy Praxis," doctoral dissertation, University of Washington, United States.

Balmain, Colette (2018), "Trajectories of Meaning in "Singularity" - the BTS Comeback Trailer: Love Yourself 轉 Tear” (accessed November 14, 2020), https://londonkorean links.net/2018/05/14/trajectories-of-meaning -in-singularity/

Big Hit Entertainment (2020), "CONNECT, BTS" (accessed August 31, 2020), https:// www.connect-bts.com/footer/about_ connect.jsp

bighitent (2020), @ bighitent, (accessed October 30, 2020) https://twitter.com/search?q = connect_bts\%20(from\%3Abighitent) \&src =typed_query

Bourdaa, Melanie (2014), “This is not Marketing.
This is HBO: Branding HBO with Transmedia Storytelling," Networking Knowledge, 7(1).

BTS (2020a), @bts_twt (accessed October 30, 2020) https://twitter.com/search?q = connect_bts $\% 20$ (from\%3Abts_twt) \&src =typed_query

BTS (2020b), @bts.bighitofficial (accessed October 30, 2020) https://twitter.com/ search? $\mathrm{q}=$ connect_bts $\% 20$ (from $\% 3 \mathrm{Abts}$ __wt ) \&src = typed_query

Campillo-Alhama,Conceptiòn, Martìnez-Sala, Alba-Marìa(2019), "Events 2.0 in the transmedia branding strategy of World Cultural Heritage Sites," El Profesional de la Información, 28(5).

Castells, Manuel (1999), "GRASSROOTING THE SPACE OF FLOWS," Urban Geography, 20(4), 294-302.

Chaudhuri, A. and Holbrook, M. (2002), "Productclass effects on brand commitment and brand outcomes: The role of brand trust and brand affect," $J$ Brand Manag, 10, 33-58.

https://doi.org/10.1057/palgrave.bm.2540100

Choi, Soobin, Gayeon Park, and Hee-Woong Kim (2019), ”A Text Mining Approach to the Analysis of BTS Fever," research proceedings, PACIS 2019.

Coombs, W. Timothy, and Sherry J. Holladay (2018), "Innovation in public relations theory and practice," Journal of Communication Management, 22(4), 382-396. 
doi:10.1108/jcom-12-2017-014.

Costa-Sánchez,Carmen, Rodríguez-Vázquez, Ana-Isabel, and López-García Xosé (2020), "Transmedia or repurposing journalism? News brands in the era of convergence. Compared study of Greek elections coverage by El País (ES), The Guardian (UK), La Repubblica (IT), and Público (PT)," Journalism, 21(9), 1300-1319. doi : 10.1177/146488491773 4053

Derhy Kurtz, Benjamin W. L. (2014), "Introduction: Transmedia Practices: A Television Branding Revolution," Networking Knowledge: Journal of the MeCCSA Postgraduate Network, 7(1). https://doi.org/10.31165/nk.2014.71.326

Dex, Robert (2020), “CONNECT, BTS: Korean boyband team up with Serpentine in worldwide free art project" (accessed August 31, 2020), https://www.standard.co.uk/ culture/bts-connect-exhibition-art-project -london-serpentine-a4333681.html

Doré, Philippa, and Peter C.v (2019), "Genre conventions in K-pop: BTS's 'Dope' music video," Continuum, 33(5), 580-589.

du Plessis, Charmaine (2018), "Prosumer engagement through story-making in transmedia branding," International Jour nal of Cultural Studies, 22(1), 175-192. doi:10.1177/1367877917750445

Eaglehawk, Wallea (2020), Idol Limerence: The Art of Loving BTS as Phenomena. Revolutionaries.
Erdem, Tülin, and Joffre Swait (2004), "Brand credibility, brand consideration, and choice," The Journal of Consumer Research, 31(1), 191-198.

Everett, Anna (2014), "Black Film, New Media Industries, and BAMMs (Black American Media Moguls) in the Digital Media Ecology," Cinema Journal, 53(4), 128-133. Featherstone, Mike, Scott Lash, and Roland Robertson (1995), Global Modernities. London: SAGE Publications.

Feng, Xiao Yu (2014), “Transmedia Branding: An Experimental Study of the Effect of Gamification on Brand Image", master's dissertation, Ritsumeikan Asia Pacific University. https://core.ac.uk/reader/60546370 Foucault, Michel (1984), "Of Other Spaces: Utopias and Heterotopias," in Architecture /Mouvement/ Continuité, Jay Miskowiec, trans.

Gheyle, Niels, and Thomas Jacobs (2017), "Content Analysis: a short overview," internal research note.

Hills, Matt (2018), “14. From Transmedia Storytelling to Transmedia Experience: Star Wars Celebration as a Crossover/ Hierarchical Space" in Star Wars and the History of Transmedia Storytelling, Amsterdam University Press.

Ibrus, Indrek, and Maarja Ojamaa (2014), "What is the Cultural Function and Value of European Transmedia Independents?", International Journal of Communication, 8, 
2283-2300.

Inside Retail Asia (2020), "Samsung and BTS enter global marketing collaboration" (accessed August 31, 2020), https://insideretail. asia/2020/02/24/samsung-and-bts-enterglobal-marketing-collaboration/

Irwansyah, Irwansyah and Annisa Fitriana Lestari (2020), "Participatory Fandom of Army BTS Indonesia in the Digital Comic on Webtoon Apps," Journal Communication Spectrum, 10(1), 46-57. http://dx.doi.org/10.36782/jcs.v9i1.1872

Jääskeläinen, Petra (2020), “BRAND VS BAND Global Marketing Analysis on Two K-pop Groups, NCT and BTS,” bacherlor degree dissertation, Kuopio, Finland.

Jenkins, Henry (2006), Convergence Culture Where Old and New Media Collide. New York: NYU Press.

Jenkins, Henry (2007), “Transmedia Storytelling 101" (accessed September 23, 2020), http://henryjenkins.org/blog/2007/03/. transmedia_storytelling__101.html

Jenkins, Henry (2011), “Transmedia 202: Further Reflections" (accessed September 23, 2020), http://henryjenkins.org/2011/ 08/defining_transmedia_further_re.html \# sthash.x5E8oaOL.dpuf

Kim, Soo (2020), "BTS and Samsung Launch Partnership With 'Connect, BTS' Augmented Reality Experience” (accessed August 31, 2020), https://www.newsweek.com/btssamsung-connect-galaxy-phone-augment ed-reality-1487967

Kim, Suk-Young (2019), "Beauty and the Waste: Fashioning Idols and the Ethics of Recycling in Korean Pop Music Videos," Fashion Theory.

Kinder, Marsha (1991), Playing with Power in Movies, Television and Video Games. University of California Press.

Kinder, Marsha (2016), “TRANSMEDIA NETWORKS” (accessed September 23, 2020), www.marshakinder.com/concepts/ o11.html

Koh, Ho Youn, and Kyungmin Baek (2020), "The Korean Diasporic Identity in the Context of K-Pop Consumption," Journal of Asian Sociology, 49(1), 1-28.

Krippendorff, Klaus (2004), Content analysis: an introduction to its methodology. Thousand Oaks, California: Sage Publications Inc.

Kwak, Hye-eun, oon-ho Kim, Sun-young Kim, Ju-eee Jung and Hyun-ju Choi (2019), "Korean dance performance influences on prospective tourist cultural products consumption and behaviour intention," Journal of Psychology in Africa, 29(3), 230-236.

Lee, Daehyung (2020), “CONNECT, BTS Seoul - 20200201" (accessed December 09, 2020), https://twitter.com/jis910408/ status/1223572768681119747

Lee, Hae-won, and Joon-ho Kim (2020), “Brand loyalty and the Bangtan Sonyeondan (BTS) Korean dance: Global viewers' perceptions," 
Journal of Psychology in Africa, 30(6), 551-558.

Lee, Jin Ha, and Anh Thu Nguyen (2020), "HOW MUSIC FANS SHAPE COMMERCIAL MUSIC SERVICES: A CASE STUDY OF BTS AND ARMY," proceedings of the 21st ISMIR conference, Montréal (October 11-16).

Lee, Jiyoung (2019), BTS, Art Revolution. Stella Kim, Myungji Chae, and Jiye Won trans. parrhesia.

Lee, Wonseok (2018), "Diversity of K-Pop: A Focus on Race, Language, and Musical Genre," master's dissertation, Bowling Green State University, United States.

Lefebvre, Henri (1991), The Production of Space. Oxford: Blackwell.

Lévy, Jaques (2014), "Inhabiting" in The Sage Handbook of Human Geography, edited by R. Lee, N. Castree, R. Kitchin, V. Lawson, A. Paasi, C. Philo, S. Radcliffe, S. M. Roberts, and C. W. J.Withers, 4568. London: Sage.

Matteo Stéphane and Dal Zotto, Cinzia (2015), "Native Advertising, or How to Stretch Editorial to Sponsored Content Within a Transmedia Branding Era” in Handbook of Media Branding. Springer, Cham. https://doi.org/10.1007/978-3-319-18236-0_12 Malpas, Jeff (2012), "Putting Space in Place: Philosophical Topography and Relational Geography," Environment and Planning D: Society and Space, 30(2), 226-242. doi:10.1068/d20810

McLaren, Courtney, and Dal Yong Jin (2020), "You Can't Help But Love Them": BTS, Transcultural Fandom, and Affective Identities," Korea Journal, 60(1), 100-127. Product-class effects on brand commitment and brand outcomes: The role of brand trust and brand affect. Journal of Brand Management, 10(1), 33-58.

https://doi.org/10.1057/palgrave.bm.2540100 Reichenbach, Hans (1958), The Philosophy of Space and Time. New York: Dover.

Saldre, Maarja and Peeter Torop (2012), "Transmedia space," in Crossmedia Innovations, Indrek Ibrus and Carlos A. Scolari eds. Peter Lang.

Scolari, Carlos Alberto (2009), "Transmedia Storytelling: Implicit Consumers, Narrative Worlds, and Branding in Contemporary Media Production," International Journal of Communication, 3, 586-606.

Shoorcheh, Mahmood (2019), "On the spatiality of geographic knowledge," Asian Geographer, 36(1), 63-80.

Soja, Edward (2010), "Seeing Nature Spatially," In Without Nature? A New Condition for Theology, edited by David Albertson, and Cabell King, 181-202. New York, NY: Fordham University Press.

Sokolova, Natalia (2012), "Co-opting Transmedia Consumers: User Content as Entertainment or 'Free Labour'? The Cases of STALKER. and Metro 2033," Europe-Asia Studies, 
64(8), 1565-1583.

Stork, Matthias (2014), "The cultural economics of performance space: Negotiating fan, labor, and marketing practice in Glee's transmedia geography" (accessed August 31, 2020), https://journal.transformative works.org/index.php/twc/article/download /490/420?inline $=1$

Tenderich, Burghardt (2013), "Design Elements of Transmedia Branding”. USC Annenberg Innovation Lab.

Tenderich, Burghardt (2014), Transmedia Branding. European Institute for Media Optimization.

Wei, Yehua Dennis (2015), "Spatiality of Regional Inequality," Applied Geography, 61(1).

Wong, Joanne (2020), "Musical Narrative in BTS' THE MOST BEAUTIFUL MOMENT IN LIFE." master's dissertation, School of Music, California state University, Fullerton,
United States.

Yang, Binbin, and Miltiadis Zisiadis (2014), "Transmedia marketing: Strengthening multiplatform user participation through storytelling” (accessed August 31, 2020), https://www.diva-portal.org/smash/record. jsf?pid $=\operatorname{diva2}: 727294 \&$ dswid $=-9682$

Yin, Robert K. (2009), Case Study Research: Design and Methods, Fourth Edition. Los Angeles: Sage.

Yin, Robert K. (2014), Case Study Research: Design and Methods. Los Angeles: Sage. Yonhap (2020), "Samsung signs partnership with BTS to boost marketing" (accessed August 31, 2020), https://en.yna.co.kr/ view/AEN20200219001100320

Zimmerman, Ana and Saura, Soraia (2016), "Body, environment and adventure: experience and spatiality," Sport, Ethics and Philosophy http://dx.doi.org/10.1080/17511321.2016. 1210207 